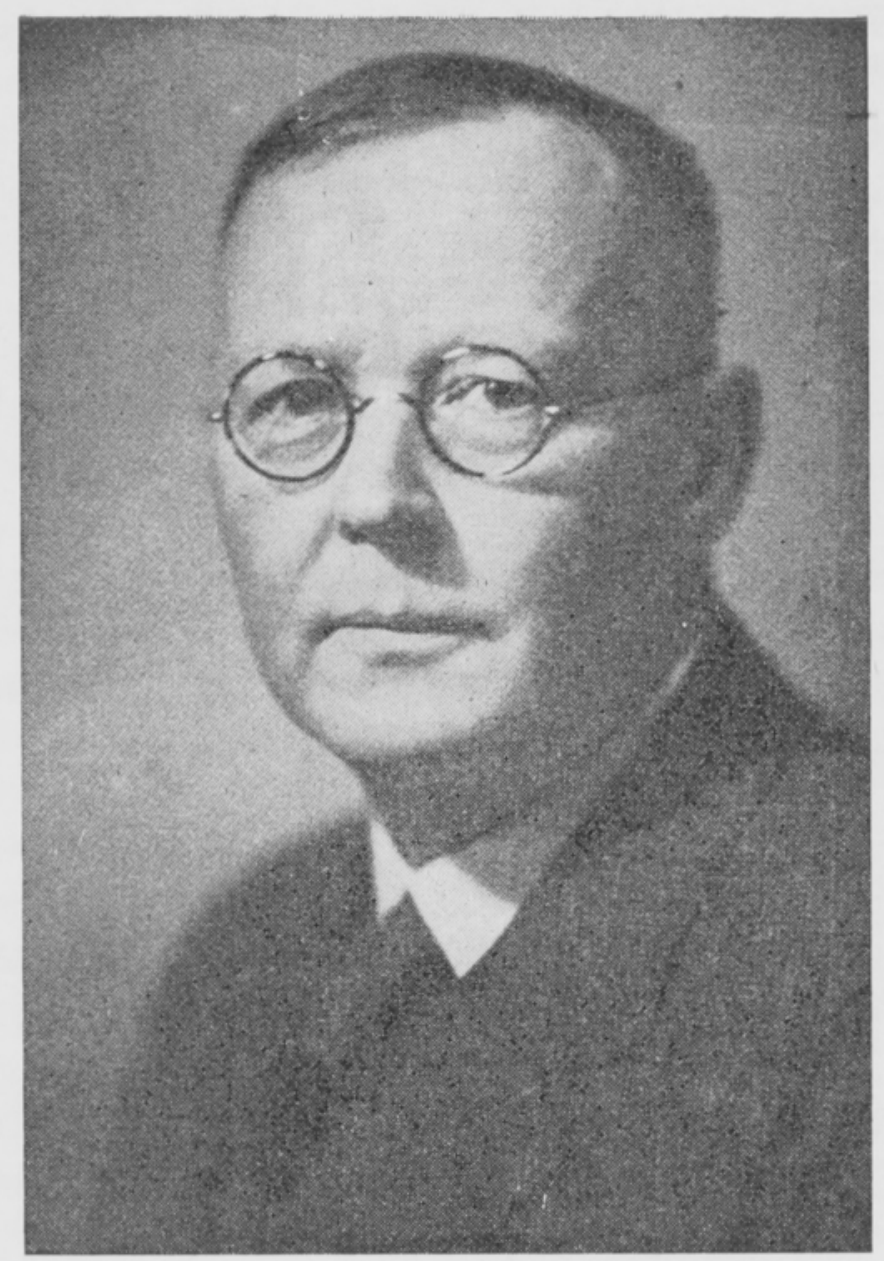

\title{
BERNHARD AARNIO
}

* 3. 6. $1876-\dagger 28.1 .1951$.

Täysinpalvellut professori, Maatalouskoelaitoksen maatutkimusosaston entinen johtaja Bernhard Aarnio, Suomen maaperätieteellisen tutkimuksen uranuurtaja on siirtynyt ajasta ikuisuuteen.

B. Aarnio (vuoteen 1895 Lemberg) oli syntynyt 3. 6. 1876 hämäläisen talonpojan poikana Vanhan Klemolan talossa Vanajan pitäjän Hattelmalan kylässä. Lapsuutensa hän vietti Nummen pitäjän Näkkilän kylässä, jossa hänen isänsä myöhemmin oli maanviljelijänä. Ylioppilaaksi hän tuli Helsingin suomalaisesta normaalilyseosta 16. 5. 1895 sekä suoritti fil. kand. tutkinnon 1903 Helsingin yliopistossa. Senjälkeen hän jatkoi opintojaan maanmittausalalla suorittaen 1906 tutkinnon silloisessa Suomen Polyteknisessä Opistossa. Hän väitteli filosofian tohtorin arvoa varten Helsingin yliopistossa 21. 4. 1915 väitöskirjallaan „Über die Ausfällung des Eisenoxyds und der Tonerde in Finnländischen Sand-und Grusböden.» Suoritettuaan fil.lis. tutkinnon 1916 hänet vihittiin fil.tohtoriksi 1917. Seuraavana vuonna $(19.12 .1918)$ hän vielä väitteli tekniikan tohtorin arvoa varten 
Teknillisessä korkeakoulussa Helsingissä väitöskirjalla »Järvimalmit eräissä Pusulan, Pyhäjärven, Lopen, Someroniemen ja Tammelan järvissä.»

Virkauransa Aarnio aloitti m a n mitt a rin a suorittaen vuosina 190410 kaikkia maanmittausalaan kuuluvia töitä Viipurin, Uudenmaan ja Ahvenanmaan lääneissä. Vuonna 1907 hänet otettiin auskultantiksi Maanmittausylihallitukseen ja 1909 määrättiin varamaanmittariksi.

Samanaikaisesti Aarnio kuitenkin työskenteli myöskin g e ologi a n alalla. Talvikausina 1907-10 hän oli Geologisen toimiston (nyk. Geol. tutkimuslaitos) kemistinä, jossa virassa hän oli vakinaisena 1912-18. Saman laitoksen vanhemman assistentin virkaa hän hoiti 1918-25. Kemistinä ollessaan hän toimi kesät kenttägeologina suorittaen a groge ologisia kartoituksia ja tutkimuksia Inkoon, Karjalohjan, Siuntion, Janakkalan, Tammelan ja Snappertunan pitäjissä. Vanhempana assistenttina hän taas johti kartoitustöitä Messukylän, Paimion ja Valkealan pitäjissä sekä Kymenlaaksossa, Etelä-Pohjanmaalla, Limingassa ja Kempeleellä.

Geologisen komissionin (nyk. Geol. tutkimuslaitos) agrogeologisella osastolla Aarnio oli määrätty johtamaan agrogeologisia tutkimuksia vuoden ajan 1922—23 osaston johtajan toht. B. Forsteruksen ollessa komissionin vt. johtajana. Komissionin sihteerinä hän toimi 1922-25. Kun agrogeologinen osasto vuoden 1926 alusta muutettiin Valtion maatutkimuslaitokseksi siirtyi Aarnio sen ensimmäiseksi vanhemmaksi agrogeologiksi, jossa virassa oli vuoteen 1931. Näinä vuosina hän johti agrogeologisten kartoitusten kenttätyöt Etelä-Pohjanmaalla (1921-25) ja LounaisSuomessa (1925—30) sekä Viipurin läänissä (1930).

Valtion maatutkimuslaitoksen vt. johtajana Aarnio oli jo muutamia kuukausia vuonna 1930 ja 1931 kunnes hänet marraskuun 17. p:nä 1931 nimitettiin laitoksen johtajaksi. Kun tämä laitos vuoden 1933 alusta siirrettiin Maatalouskoelaitokseen sen maatutkimusosastoksi määrättiin Aarnio sen ensimmäiseksi johtajaksi ja professoriksi. Tässä asemassa hän täydensi uraa uurtavan työnsä maaperätutkimuksen alalla. Agrogeologiset kartoitustyöt suoritettiin silloin Loimaan ja Salon alueilla sekä Helsingin, Nivalan, Nummen ja Pusulan alueilla sekä Karjalan kannaksella. Näiden kartoitusten yhteydessä on suoritettu suuri määrä tutkimuksia, joista toisessa yhteydessä enemmän.

Koko virkauransa ajan Aarnio suoritti myöskin tutkimusalansa o p e t u st o i mintaa. Hän oli mineralogian assistenttina Teknillisessä korkeakoulussa 1909-10 ja 1912 -19 sekä Helsingin yliopiston maanviljelyskemian assistenttina 1918 - 19, dosenttina 1919 alkaen sekä maaperäopin opettajana myöskin 1919 alkaen. Vakinaisena propedeuttisen aineen opettajana hän oli 1930 alkaen.

Aarnio toimi virallisena vastaväittäjänä seuraavien väitöskirjojen tarkastuksessa: maanviljelysinsinööri Pekka Kokkosen väitöskirja »Viemärien kuntoon vaikuttavista tekijöistä» 1.3. 1924 Helsingin yliopistossa, insinööri Lauri Keson väitöskirja "Kulttuuriteknillisiä maaperätutkimuksia erikoisesti ojaetäisyyttä silmälläpitäen» 26. 5. 1930 Teknillisessä korkeakoulussa, maat. metsät. kand. Erkki Kivisen väitöskirja "Suokasvien ja niiden kasvualusta kasvinravintoainesuhteista" 11. 3. 1933 Helsingin yliopistossa ja maat. metsät. kand. Jouko Vuorisen väitös- 
kirja "Untersuchungen über die Koagulation des schweren Glazialtons» 31. 5. 1939 Helsingin yliopistossa.

Aarnio oli erityisen hyvin hoitanut suhteita muihin maihin. Hän oli itse opiskellut ja työskennellyt Berlinin maanviljelyskorkeakoulussa 1911 sekä osallistunut Berlinin yliopiston toimeenpanemaan maaperäretkeilyyn Badeniin, Württembergiin ja Bayeriin sekä tutustunut Böhmin Landeskulturat'in tutkimustapoihin prof. J. Kopecky'n johdolla samana vuonna. Berlinin yliopiston Geol.Paläontologisella laitoksella hän työskenteli 1914. Valtion apurahalla hän teki opintomatkan Saksaan, Unkariin ja Sveitsiin 1921-22. Vuonna 1924 Aarnio teki opintomatkan Italiaan, Sveitsiin, Itävaltaan, Tšekkoslovakiaan, Saksaan, Hollantiin, Englantiin, Tanskaan ja Ruotsiin. Valtion apurahalla hän kävi tutustumassa Ruotsin maantutkimukseen sekä osallistui maantutkimusretkeilyyn Unkarissa 1926. Vuonna 1936 hän vielä teki valtion apurahalla opintomatkan Saksaan, Itävaltaan ja Unkariin. Aarnio oli myöskin tärkeissä tehtävissä monissa kansainvälisissä kongresseissa. Hän oli Suomen edustajana ja kutsuttuna referenttinä kansainvälisessä maaperäkongressissa Roomassa 1924. Hän oli Suomen edustajana myös 1929 Kansainvälisen maatutkimusseuran maaperäkartoituskomission konferenssissa Budapestissa. Tämän seuran kemiallisen komission ja alkalikomission varapuheenjohtajaksi hänet valittiin Rooman konferenssissa 1924 ja Washingtonin kongressissa 1927 sekä Moskovan kongressissa 1930. Vuonna 1948 Wienin maatalouskorkeakoulu kutsui prof. Aarnion kunniatohtorikseen.

Aarnio kuului aktiivisesti toimivana jäsenenä moniin koti- ja ulkomaisiin t ieteellisiin seuroihin. Näistä mainittakoon Geologinen yhdistys (puh.joht. 1918), Kemistsamfundet, Suomalaisten teknikkojen seura, Suomen maataloustieteellinen seura (puh.joht. 1929), Nordisk Jordbrugsforskeres Forening (johtok. 1926), Suomen maantieteellinen seura, Deutsche Geologische Gesellschaft, Naturforschender Verein in Danzig, Kansainvälinen maatutkimusseura, Suomalainen tiedeakatemia, Maatalousakatemia (esimies 1938-39).

Aarnion tieteelliset tutkimukset ja hänen laaja julkaisutoimintansa keskittyy maaperätieteen keskeisiin kysymyksiin. Ennen vuotta 1920 oli hänen tutkimuksissaan etualalla maaperän kolloideihin liittyvät kysymykset. Näitä hän on käsitellyt 13:ssa eri julkaisussa, joihin kuuluvat m.m. hänen molemmat väitöskirjansa. Keskeisenä tutkimuskohteena on niissä ollut raudan esiintyminen meikäläisessä maaperässä ja sen saostuminen sekä rauta-, aluminiumja piihappogeelien hygroskooppisuus.

Agrogeologisia karttoja ja niitä koskevia esityksiä Aarnio julkaisi (1916-38) kaikkiaan kahdeksantoista. Näistä ensimmäiset olivat yksityisten tilojen ja kylien tai erikoisten alueiden tutkimuksia, joissa tärkeällä sijalla olivat edellä esitetyt kolloideihin liittyvät maaperäkysymykset: Myöhemmin tutkimukset kohdistuivat laajempiin alueisiin. Ensimmäisenä sellaisena oli Paimion pitäjän agrogeologinen kartta (1: 50000$)$ (1924). Etelä-Pohjanmaan laaja alue kartoitettiin taloudellisen kartan (1:100000) pohjalle ja julkaistiin 1927. Turun (1930), Loimaan (1933) ja Salon (1935-38) karttalehdet tutkittiin mittakaavassa 1: 20000 , mutta kartat julkaistiin 1:50000. Näillä kartoituksilla on varsinaisesti Suomen maape- 
räntutkimus perustettu ja maaperäntuntemukselle luotu pohja. Ilman tämäntapaista järjestelmällistä työtä ei olisi voitu maaperätieteessä päästä niihin saavutuksiin, joihin Aarnio pääsi.

Maan happamuntta Aarnio selvitteli kaikkiaan 27:ssä julkaisussa (1914-36). Erityisesti tämä kysymys tuli maaperäkartoituksen yhteydessä tutkituksi 1920luvulla, jolta ajalta ovat useimmat hänen happamuutta ja maan kalkkikysymystä koskevat julkaisunsa.

Happamuuden rinnalla ovat tutkimuskysymyksinä olleet mantumuotojen selvittely (1921—40) yhteensä 13 esitystä sekä maalajit. Viimemainittuja on Aarnio käsitellyt (1924-44) kaikkiaan 34:ssä julkaisussaan ja hänen ansiotaan on, että meillä maalajit ovat hyvin tutkittuja ja käytännöllinen maalajiryhmittely pääasiassa niiden tutkimusten perusteella on ollut mahdollinen. Erityisesti Aarnio harrasti maaperäkysymysten alueellista selvittelyä artikkeleissa käytännön miehille tarkoitetuissa teoksissa.

Maaperän ja kasvillisuuden suhde ja maan ravinteisums ja viljavuus on tutkimuksen ja käsittelyn aiheena 28:ssa Aarnion julkaisussa (1921-43). Nämä kysymykset ovat erityisesti keskeisinä 1930-luvun tutkimuksissa. Maan lannoitusja kalkitustarpeen määrittäminen, luontaisen metsämaan ravinteisuus, maaperän viljelysominaisuudet, maan kasvukykyyn vaikuttavat seikat y.m. ovat kysymyksiä, jotka ovat valmistaneet "maaperää» uusille tutkimusmenetelmille maatalouden edistämiseksi. Ruotsissa tuo maan ravinteisuuden kemiallinen selvittäminen pääsikin yleiseksi jo 1940-luvulla, mutta meillä varsinaisesti vasta tällä vuosikymmenellä.

Aarniolta riitti aikaa ja harrastusta jossain määrin myös lannoitteisiin ja lannoitukseen sekä yleiseen koetoiminnan organisatioon.

Keskuudestamme on nyt poissa kauaskatseinen, rehellinen tutkija ja tiedemies. Hän piti tiukasti kiinni siitä, minkä hän oli oikeaksi todennut tai tutkimuksillaan selvittänyt. Mutta hän tunnusti myös avoimesti, että se mitä nyt tiedetään ei ole lopullista. Uudet käsitykset kehittyvät tutkimusten edistyessä ja kukin tutkija on avaamassa vakoa vain omalta osaltaan. Uudet avatut vaot tuovat esiin aina uutta, jonka selvittäminen ja ymmärtäminen perustuu vanhan tuntemiseen.

Kauaskatseisena hän myös piti huolta jälkipolven kehittymisestä. Jo ensimmäisinä ylioppilasvuosina hän vakavasti muistutti meitä nuoria kesätutkijoita nopeasta valmistumisesta, koska hän näki vuosien taakse. Hän näki tuolien, myöskin omansa, jäävän tyhjäksi kerran ja tunsi vastuuta työn jatkumisesta. Väsymättä hän myös innosti nuorempia ja ohjasi tutkimusten suorittamista.

Bernhard Aarnio oli minulle henkilökohtaisesti aina erinomainen esimies, hyvä työtoveri ja läheinen ystävä. Erityisesti on mielessäni se antoisa jäähyväiskierros, joka hänen johdollaan tehtiin hänen viimeisenä johtajavuotenaan halki Suomen. Se oli kuin tutkimustehtävien luovutustilaisuus. Erittäin miellyttävä oli myös hänen asenteensa tutkimuslaitokseensa ja sen tutkijoihin senkin jälkeen, kun hän jo seurasi heidän toimintaansa sivusta. - Aika on Bernhard Aarnion kohdalla loppunut. Suokoon Kaikkivaltias Jumala siunauksensa veljemme Aarnion muistolle.

\section{Jouko Vuorinen.}




\title{
BERNHARD AARNIO
}

\author{
* 3. $6.1876-\dagger 28.1 .1951$
}

Professor emeritus, der frühere Leiter der Bodenkundlichen Abteilung der Landwirtschaftlichen Versuchsanstalt und der Bahnbrecher der Bodenforschung in Finnland, Bernhard Aarnio, ist aus dem Zeitlichen ins Ewige eingegangen.

B. Aarnio (bis 1895 Lemberg) wurde am 3. 6. 1876 als Sohn eines tawastländischen Bauers im Hause Vanha Klemola im Dorf Hattelmala, Kirchsp. Vanaja, nicht weit von der Stadt Hämeenlinna, geboren. Seine Kindheit verbrachte er im Dorf Näkkilä im Kirchsp. Nummi, wohin der Vater als Landwirt übergesiedelt war. Student aus dem Finnischen Normallyzeum in Helsinki 16. 5. 1895, legte er 1903 die philosophische Kandidatenprüfung an der Universität in Helsinki ab, setzte sodann seine Studien auf dem Gebiet der Landmesserei fort und schloss dieselben 1906 mit einem Examen am damaligen Finnischen Polytechnischen Institut ab. Die philosophische Doktorswürde erwarb er sich am 21. 4. 1915 mit einer Abhandlung "Über die Ausfällung des Eisenoxyds und der Tonerde in finnländischen Sandund Grusböden». Nach Erledigung der philosophischen Lizenziatprüfung 1916 wurde er 1917 zum Doktor der Philosophie promoviert. Im folgenden Jahre (19. 12. 1918) disputierte er noch zur Erlangung der technischen Doktorswürde mit einer Abhandlung betitelt "Järvimalmit eräissä Pusulan, Pyhäjärven, Lopen, Someroniemen ja Tammelan järvissä» (Die See-Erze in einigen Seen der Kirchspiele Pusula, Pyhäjärvi, Loppi, Someroniemi und Tammela) an der Technischen Hochschule in Helsinki.

Seine amtliche Laufbahn begann Aarnio als Landmesser und arbeitete zunächst in den Jahren 1904-10 in den Länen Viipuri, Uusimaa und Ahvenanmaa. Im Jahre 1907 wurde er als Auskultant in die Landmessereioberverwaltung aufgenommen und 1909 zum Vizelandmesser ${ }^{\circ}$ erordnet.

Gleichzeitig betätigte sich aber Aarnio auch auf dem Gebiet der Geologie. In den Wintersemestern der Jahre 1907-10 diente er als Chemiker bei der Geologischen Kommission (der heutigen Geologischen Forschungsanstalt), bekleidete sodann diesen Posten etatsmässig 1912 - 18 und danach 1918 - 25 das Amt des älteren Assistenten an der gleichen Anstalt. Die Sommer seiner Chemikerjahre verbrachte er als Feldgeologe in der Provinz und führte in den Kirchspielen Inkoo, Karjalohja, Siuntio, Janakkala, Tammela und Snappertuna agrogeologische Kartierungen und Untersuchungen aus. Als älterer Assistent wiederum leitete er die Kartierungs- 
arbeiten in den Kirchspielen Messukylä, Paimio und Valkeala sowie im Kymijokital, in Süd-Pohjanmaa, Liminka und Kempele.

Als der damalige Leiter der Agrogeologischen Abteilung der Geologischen Kommission, Dr. B. Frosterus, 1922-23 zum stellvertretenden Leiter der Geologischen Komission abberufen war, leitete Aarnio während des genannten Semesterjahres die agrogeologischen Forschungen an der genannten Abteilung. Als Sekretär der Kommission wirkte er 1922 - 25. Als die Agrogeologische Abteilung im Anfang des Jahres 1926 zum Staatlichen Bodenuntersuchungsinstitut umorganisiert wurde, übernahm Aarnio den Posten des älteren Agrogeologen daselbst und innehatte ihn bis zum Jahre 1931. In diesen Jahren leitete er die Feldarbeiten der agrogeologischen Bodenkartierungen in Süd-Pohjanmaa (1921-25), SüdwestFinnland (1925-30) und im Län Viipuri (1930).

Nachdem Aarnio schon während einiger Monate in den Jahren 1930 und 1931 das Amt des stellvertretenden Leiters des Staatlichen Bodenuntersuchungsinstituts versorgt hatte, wurde er am 17. November 1931 zum Leiter der Anstalt ernannt. Als die Anstalt im Beginn des Jahres 1933 der Landwirtschaftlichen Versuchsanstalt als deren Bodenkundliche Abteilung unterstellt wurde, wurde Aarnio zugleich mit dem Titel und der Würde eines Professors zu deren erstem Leiter verordnet. In dieser neuen Stellung vervollkommnete er sein bahnbrechendes Wirken auf dem Gebiet der Bodenforschung. Die agrogeologische Bodenkartierung war zu jener Zeit eben in den Gebieten von Loimaa, Salo, Helsinki, Nivala, Nummi und Pusula im Gange. In Verbindung mit diesen Kartierungen ist eine beachtliche Menge von Forschungsarbeit geleistet worden, die in anderem Zusammenhang näher zur Sprache genommen wird.

Während seiner ganzen amtlichen Laufbahn leistete Aarnio auch wissenschaftliche Unterrichtstätigkeit auf dem von ihm vertretenen Gebiet. Er arbeitete als Assistent der Mineralogie an der Technischen Hochschule 1909-10 und als Assistent der Agrikulturchemie an der Universität Helsinki 1918 - 19, war Dozent daselbst seit 1919 und desgleichen seit 1919 Lehrer der Bodenkunde. Als ordentlicher Lehrer des propedeutischen bodenkundlichen Unterrichts wirkte er seit 1930.

Bei folgenden akademischen Disputationen stand Aarnio als ex officio Opponent: 1. 3. 1924 Agrikulturingenieur Pekka Kokkonen mit der Abhandlung »Viemärien kuntoon vaikuttavista seikoista» (Über die auf den Zustand der Abzuggräben einwirkenden Faktoren) an der Universität Helsinki; 26. 5. 1930 Ingenieur Lauri Keso mit der Abhandlung "Kulttuuriteknillisiä maaperätutkimuksia erikoisesti ojaetäisyyttä silmälläpitäen» (Kulturtechnische Bodenuntersuchungen mit besonderer Beachtung des Grabenabstandes) an der Technischen Hochschule; 11. 3. 1933 Agronom Erkki Kivinen mit der Abhandlung "Suokasvien ja niiden kasvualustan kasvinravintoainesuhteista» (Über die Pflanzennährstoffverhältnisse der Moorpflanzen und ihres Standbodens) an der Universität Helsinki; 31. 5. 1939 Agronom Jouko Vuorinen mit der Abhandlung "Untersuchungen über die Koagulation des schweren Glazialtons» an der Universität Helsinki.

Aarnio sorgte in ausgezeichneter Weise für die Beziehungen zum Ausland. Er hatte selbst 1911 an der Landwirtschaftlichen Hochschule in Berlin studiert 
und gearbeitet und dabei an der von der Berliner Universität veranstalteten bodenkundlichen Exkursion nach Baden, Württemberg und Bayern teilgenommen, ebenso machte er sich im gleichen Jahre unter der Leitung von Professor J. Kopecky mit den Arbeitsweisen des Böhmer Landeskulturats vertraut. Im Jahre 1914 arbeitete er im Geologisch-Paläontologischen Institut der Universität Berlin. 1921—22 unternahm er als Staatsstipendiat eine Studienreise nach Deutschland, Ungarn und der Schweiz. Bei einer zweiten Studienreise im Jahre 1924 besuchte er die Länder Italien, Schweiz, Österreich, Tschechoslowakei, Deutschland, Holland, England, Dänemark und Schweden. Abermals als Staatsstipendiat reiste er 1926 nach Schweden, um einen Einblick in die dortige Bodenforschung zu gewinnen, und nahm in demselben Jahre an einer bodenkundlichen Exkursion in Ungarn teil. Im Jahre 1936 bereiste er noch mit Hilfe eines Staatsstipendiums Deutschland, Österreich und Ungarn. Aarnio bekleidete auch wichtige Ämter bei zahlreichen internationalen Kongressen. Im Jahre 1924 beteiligte er sich als offizieller Vertreter Finnlands und als eingeladener Referent am Internationalen Kongress für Bodenkunde in Rom. Er vertrat Finnland auch bei der Konferenz der Bodenkartierungskommission der Internationalen Bodenkundlichen Gesellschaft in Budapest 1929. In den Kongressen in Rom 1924, Washington 1927 und Moskau 1930 wurde er zum Zweite Vorsitzender der Chemischen Kommission und der Alkalisubkommission gewählt. Im Jahre 1948 berief die Landwirtschaftliche Hochschule in Wien ihn zu ihren Ehrendoktor.

Aarnio war Mitglied in zahlreichen einheimischen und ausländischen wissenschaftlichen Vereinigungen. Von diesen mögen erwähnt werden: die Geologische Vereinigung Finnlands (Vorsitzender 1918), Kemistsamfundet, der Verband Finnischer Techniker, die Agrikulturwissenschaftliche Gesellschaft in Finnland (Vorsitzender 1929), Nordiske Jordbrugsforskeres Forening (Vorstandsmitglied 1926), die Geographische Gesellschaft in Finnland, die Deutsche Geologische Gesellschaft, der Naturforschende Verein in Danzig, die Internationale Bodenkundliche Gesellschaft, die Finnische Wissenschaftsakademie und die Landwirtschaftsakademie (Präsident 1938-39).

Die wissenschaftliche Forschungs- und die umfassende Publikationstätigkeit Aarnios sind auf die zentralen Fragen der Bodenkunde konzentriert gewesen. Vor dem Jahre 1920 standen die mit den Bodenkolloiden verbundenen Fragen im Vordergrund seiner Forschungen. Diese sind von ihm in insges. 13 Arbeiten, darunter auch seine beiden Dissertationen, behandelt worden. Den zentralsten Gegenstand hat in ihnen das Auftreten des Eisens in unseren Böden und dessen Ausfällung sowie die Hygroskopizität der Eisen-, Aluminium- und Kieselsäuregele dargestellt.

Agrogeologische Karten und auf diese bezügliche Darstellungen veröffentlichte Aarnio in den Jahren 1916-38 insgesamt 18. Von diesen betrafen die ersten einzelne Gehöfte, Dörfer oder spezielle Gebiete, und eine wichtige Stellung nahmen bei diesen Untersuchungen die obenerörterten, auf die Kolloide bezüglichen Bodenprobleme ein. Die späteren Untersuchungen bezogen sich auf ausgedehntere Gebiete. Den Beginn bildete die agrogeologische Karte des Kirchspiels Paimio im Massstab 1: 50000 (1924). Das weite Gebiet von Süd-Pohjanmaa wurde agrogeo- 
logisch auf die Kartenblätter der Ökonomischen Karte von Finnland (1: 100 000) aufgenommen und im Jahre 1927 herausgegeben. Die Kartenblätter Turku (1930), Loimaa (1933) und Salo (1935-38) wurden im Massstab 1: 20000 aufgenommen, aber im Massstab 1: 50000 herausgegeben. Mit diesen Aufnahmen war der eigentliche Grund für die Bodenforschung und die Kenntnis der Bodenverhältnisse in Finnland geschaffen. Ohne ein solches systematisches Vorgehen wäre man in der Bodenforschung bei uns lange nicht zu derartigen Leistungen gekommen, wie sie durch Aarnio erzielt worden sind.

Mit der Bodenazidität hat sich Aarnio 1914-36 in insges. 27 Arbeiten befasst. Eine besondere Aufmerksamkeit wurde dieser Frage in Verbindung mit den Bodenkartierungen der 20er Jahre zugewandt, und aus dieser Zeit stammen auch die meisten auf die Bodenazidität und die Kalkfrage des Bodens bezüglichen Untersuchungen Aarnios.

Neben der Bodenazidität wurden auch die Bodenbildungsformen (13 Veröffentlichungen in den Jahren 1921-40) und die Bodenarten (insges. 34 Veröffentlichungen in den Jahren 1924-44) zum Gegenstand der Untersuchungen gemacht. Dank Aarnio sind die Bodenarten bei uns heute gut erforscht, und ihre praktische Einteilung ist hauptsächlich eben auf Grund dieser Untersuchungen möglich geworden. Besonders gern setzte sich Aarnio über Fragen betreffs der regionalen Klärung der Bodenprobleme in für den Mann der Praxis herausgegebenen Sammelwerken auseinander.

Die gegenseitigen Beziehungen von Boden und Vegetation sowie der Nährstoffgehalt und die Fruchtbarkeit des Bodens finden Behandlung in insges. 28 Arbeiten aus den Jahren 1921-43. Insbesondere in den 30er Jahren nehmen diese Fragen eine zentrale Stellung in der wissenschaftlichen Produktion Aarnios ein. Die Bestimmung des Düngungs- und Kalkungsbedarfs der Böden, der Nährstoffgehalt des natürlichen Waldbodens, die Kultureigenschaften des Bodens, die auf die Wachstumskraft des Bodens einwirkenden Umstände u. dgl. m. sind Fragen, die den Weg für neue Untersuchungsmethoden zur Förderung der Landwirtschaft bereitet haben. In Schweden erlangte denn auch jene chemische Erschliessung der Böden schon in den 40er Jahren allgemeine Verbreitung, bei uns jedoch in eigentlichem Sinne erst während dieses Jahrzehnts.

In gewissem Umfang fand Aarnio Zeit und Interesse auch für Fragen betreffend Düngemittel und Düngung sowie die allgemeine Organisation des Versuchswesens.

Wir vermissen jetzt einen weitblickenden, ehrlichen Forscher und Wissenschaftsmann. Er hielt fest daran, was er für richtig befunden oder durch seine Untersuchungen geklärt hatte. Er gestand aber auch ehrlich, dass das, was wir jetzt wissen, keineswegs endgültig ist. Neue Auffassungen erwachsen aus der ständig fortschreitenden Forschung, und jeder Forscher pflügt nur seine eigene bescheidene Furche. Aber neuaufgebrochene Furchen bringen stets Neues an den Tag, dessen Erschliessung und Verständnis nur über die Kenntnis und Erkenntnis des Alten geschehen kann.

Als ein weitblickender Mann sorgte Aarnio auch für den Nachwuchs. Schon 
in den ersten Studentenjahren warnte er uns junge Sommerassistenten ernstlich vor einer Verzögerung der Studien, denn er sah über Jahre hinweg in die Zukunft. Er sah die Lehrstühle, auch seinen eigenen, einmal leer werden und empfand eine Verantwortung für die Fortführung der Arbeit. Unermüdlich regte er die jungen Forscher zur Arbeit an und stand ihnen bei der Ausführung ihrer Untersuchungen zur Seite.

Für mich persönlich war Bernhard Aarnio stets ein ausgezeichneter Vorgesetzer, ein guter Arbeitskamerad und ein naher Freund. Immer werde ich an die ergiebige Abschiedsrundfahrt zurückdenken, die unter seiner Leitung in seinen letzten Dienstjahr durch das Land unternommen wurde. Das ganze war wie ein grosser Überlieferungsakt der Forscheraufgaben. Ausserordentlich sympathisch war sein Verhalten zu dem von ihm geleiteten Forschungsinstitut und dessen Forscherkräften auch dann noch, als er schon deren Wirken von abseits verfolgte. - Die Zeit ist für Bernhard Aarnio zuendegelaufen. Es segne Allmächtiger Gott das Andenken unseres Bruders Aarnio.

\title{
Jouko Vuorinen.
}

\author{
PROFESSORI B E R N H A R D A A R N I O N JULKAISUT.
}

Publikationen von Professor Bernhard A a rnio.

1908 - Savien kokoomuksesta ja ominaisuuksista. Suomen Maamittari-Yhd. Aikak., 17, p. 119123. Helsinki.

1909 - Maamittarien käytännöllisestä ammattiopetuksesta. Ibid., 18, p. 392-397.

1911 - Maalajeista ja niiden kartoituksista. Ibid., 20, p. 9-17.

- Olosuhteista maanmittausalalla, joissa ehkä olisi korjaamisen varaa. Ibid., 20, p. 124-127.

- Maalajikartoista. Ibid., 20, p. 289-296, 365-370.

- H. Stremmen kanssa (mit H. Stremme). Die Bestimmung des Gehaltes der anorganischen Kolloide in Zersetzten Gesteinen und deren tonigen Umlagerungsprodukten. Ztschr. für praktische Geologie, 19, p. 329-351. Halle a. d. S.

1912 - Kolloidisista aineista ja niiden merkityksestä maissa. Suomen Maamittari-Yhd. Aikak., 21, p. 6-17. Helsinki.

- Nykyaikaisista maiden tutkimuksista ja kartoituksista. I. Ibid., 21, p. $367-376$.

1913 - Nykyaikaisista maiden tutkimuksista ja kartoituksista. II. Ibid., 22, p. 317-333.

- Experimentelle Untersuchungen zur Frage der Ausfällung des Eisens in Podsolböden. Int. Mitt. für Bodenk., 3, p. 131-140. Wien-Berlin-London.

1914 - Die Bestimmung der Acidität der Bodenlösung. La Pédologie, 16, N:o 3, p. 9-11. Petrograd.

- Zur Kenntnis einigen allophanoidartigen Tone. Centralbl. für Mineral., Geol.u.Paläontol. 1914, N:o 3, p. $69-75$. Stuttgart.

1915 - Maanlaatumuodostuminen. Suomen Maanmittari-Yhd. Aikak., 24, p. 259-271. Tampere. Über die Ausfällung des Eisenoxyds und der Tonerde in Finnländischen Sand- und Grusböden. Diss., Geol.Kom.geotekn. tied.ant., 16, p. 1-76, 1 kartta. Helsinki; Venäjäksi: La Pédologie, 17, N:o 2, p. 1-50, N:o 3, p. 1-23. Petrograd.

1916 - Karjalohjan kirkonkylän eteläpuolella oleva seutu ja Immolan maatila. Kartta ja selitys. Agrogeologisia karttoja N:o 1, p. 1-59, 3 karttaa $(1: 2.000 \& 1: 25.000)$. Helsinki. 
1917 - Trakten söder om Karislojo kyrkoby och Immola egendom. Karta och beskrivning. Agrogeol. kartor N:o 1, p. $1-57,3$ karttaa $(1: 2.000 \& 1: 25.000)$. Helsinki.

- Ekonomiset karttamme. Summary: On economical Maps. Geol. Kom.geotekn.tied.ant., 19, p. 1-10. Helsinki; Suomen Maataloustiet. sẻur julk., 2, p. 95-104. Engl. Summary. Helsinki.

— Våra ekonomiska kartor. Geol. Kom.geotekn.medd., 2, p. 1-9. Engl. Summary. Helsimki.

— Järvimalmit eräissä Pusulan, Pyhäjärven, Lopen, Someroniemen ja Tammelan järvissä. Geol. Kom.geotekn.tied.ant., 20, p. 1-61, 16 kuvaa, 7 karttaa (1:16.000). Diss. Helsinki.

- Sjömalmbildningen i södra Finland. Helsingin Geol. Yhd. tiedonant. 1917-18, p. 1.; Teknikern, 26, p. 119. Helsinki.

1918 - Om sjömalmerna i några sjöar i Pusula, Pyhäjärvi, Loppis, Somerniemi och Tammela socknar. Ref.: Über die Seeerzbildung in einigen südfinnischen Binnenseen. p. 1-77, 16 kuvaa, 7 karttaa $(1: 16.000)$. Helsinki.

1920 - Mustiala. Agrogeol. karttoja N:o 3, p. 1-75, 3 karttaa (1: 16.000), 7 kuvaa. Helsinki. Myös ruotsiksi (Auch auf Schwedisch).

- Suomen maaperän kalkinpitoisuudesta. Geol. Kom.geotekn.tied.ant., 27, p. 1-23. Helsinki.

— Om de finska jordmånernas kalkhalt. Geol. Kom.geotekn.medd. 27, p. 1-23. Helsinki.

- Hygroskooppisuus geeleissä $\mathrm{Fe}_{2} \mathrm{O}_{3}, \mathrm{Al}_{2} \mathrm{O}_{3}$ ja $\mathrm{SiO}_{2}$ käsittelyn jälkeen eri lämmöissä. Geol. Kom.geotekn.tied.ant., 25, p. 45-55. Helsinki.

- Hygroskopiciteten hos geler av $\mathrm{Fe}_{2} \mathrm{O}_{3}, \mathrm{Al}_{2} \mathrm{O}_{3}$, och $\mathrm{SiO}_{2}$ vid olika temperatur. Ref.: Die Hygroskopizität der Gele $\mathrm{Fe}_{2} \mathrm{O}_{3}, \mathrm{Al}_{2} \mathrm{O}_{3}$ und $\mathrm{SiO}_{2}$ bei verschiedenen Temperaturen., p. 67. Helsinki.

— Om sjömalmerna i några sjöar i Pusula, Pyhäjärvi, Loppis, Somerniemi och Tammela socknar. Ref.: Über die Seeerzbildung in einigen südfinnischen Binnenseen. Suomen Maantiet. Seur. julk., Fennia 41, p. 1-77, 16 kuvaa, 7 karttaa $(1: 16.000)$. Helsinki.

1921 - „Vanhat kauramaat» ryöstöviljelystä Suomessa. Geol. Kom.geotekn.tied.ant., 29, p. 1-36. Helsinki.

- Utsugningskultur i Finland, s.k. Gamla havrelandsmarker. Geol. Kom.geotekn.medd., 29, p. $1-36$. Helsinki.

- Jankkomuodostumista. Geol. Kom.geotekn.tied.ant., 30, p. 1-45. Helsinki.

- Om alvtyper. Geol. Kom.geotekn.medd., 30, p. 1-46. Helsinki.

- Suomen maaperän kalkinpitoisuudesta. Tekn. Aikakausl., 11, p. 382-393. Helsinki.

1922 - Über die Salzböden (Alaunböden) des humiden Klimas in Finnland. Int. Mitt.f. Bodenk., 12, p. 180-185. Wien - Berlin - London; Compt. rend. de la Conf. Extraord. (III. Int.) Agropéd. á Prague 1922, p. 186-192. Praha.

- Die Absorption des Ammoniumions aus Lösungen verschiedener Ammoniumsalze und die Einwirkung von Elektrolyten auf dieselbe. Ztschr.Pfl., Düng. u. Bodenk. Teil A, 1: 5, p. $320-325$. Berlin.

— Die Entstehung der Eisensulfidtone. Ztschr.f. praktische Geologie, 30, p. 122-124. Halle a. d. S.

1923 - Suomen maaperän suhde kasvillisuuteen. Maatalous, 26, p. $310-324,343-349$. Porvoo Helsinki.

- W. Brennerin kanssa (mit W. Brenner). Zur Kenntnis der Szikböden in Ungarn. Int. Mitt. f. Bodenk., 13:5-6, p. 177-183. Berlin.

1924 - Suomi (Finnland). Allgemeine geophysikalische Beschreibung. Mémoires sur la cartographie des sols dans divers pays de l'Europe, Amerique, Afrique et Asie. Memoriile Institutului geologic al Romaniei, II, p. 74-83. Bukarest.

— Litorinasaven tumman värin syistä. Helsingin Geol. Yhd.tied.ant. 1921-1923, p. 7-11. Forssa.

- Maaperästä. Maapallo I, p. 213-218. Helsinki.

- Huomioita maan happamuuden vaikutuksesta viljelyskasveihin Hollannissa. Maatalous, 18, p. 313-315. Porvoo - Helsinki. 
— Paimion pitäjä. Deutsch. Ref. Agrogeol. karttoja N:o 4, p. 1-25, 1 kartta (1:50.000). Helsinki.

- Sur la formation et la classification du sol. Abstract: Soil Formation and Soil Classification. Actes de la IV. Conf. Int. de Pédol. Rome 12-19 mai 1924, Vol. III, p. 310-313. Roma,

- Maanlaatumuodostuminen ja luokitus. Suomen Maantiet. Seur. aikak. Terra, p. 130140. Helsinki.

- H. Stremmen kanssa (mit H. Stremme). Zur Frage der Bodenbildung und Bodenklassifikation. Agrogeol. julk. N:o 17, p. 1-48. Helsinki; Mémoires sur la nomenclature et la classification des sols dans les pays suivants Allemagne etc., p. 71-114. Helsinki.

1925 - Les terres brunes en Fennoscandia. Compt. rend. de l'Ass. Int. de la Sci. du Sol, p. 7785. Berlin.

- Braunerde in Fennoskandia. Mitt. Int. Bodenk. Ges., Bd. I (NF) N:o 2, p. 77-84. Berlin.

- Maan reaktiosta. Maatalous, 18, p. 249-255. Porvoo - Helsinki.

— Peltomaiden reaktio ja väkilantojen käyttö. Ibid., 18, p. 290-294.

- Organisationen av lantbrukets försöksverksamhet i Finland. Nordisk Jordbrugsf., p. 2630. København.

1926 - Ueber Bodenreaktion. Résumé: Sur la réaction du sol, p. 483. Abstract: Soil Reaction, p. 484. Act. de la IV. Conf. Int. de Pédologie Rome 12-19 mai 1924, Bd. II, p. 481-483. Rome.

- Om de finska jordarterna och särskildt deras bördighet. Nordisk Jordbrugsf., p. $370-377$, 1 kartta. København.

- Die Einwirkung von Elektrolyten auf die Adsorption des Wasserstoffions. Mitt. Int. Bodenk. Ges., Bd. II: 1. p. 1-7. Berlin.

— Maalajit kentällä määrättyinä. Valtion Paikalliskoetoimintakursseilla Helsingissä 9. — 10. pnä huhtikuuta 1926 pidettyjä esitelmiä, p. 9-12. Helsinki.

- Maalajien jakaantuminen Etelä-Pohjanmaalla. „Vaasa», N:o 214/18. 9. 1926, p. 4, 7. Vaasa.

- Antti Salmisen kanssa (mit Antti Salminen). Suomen peltomaiden reaktiomääräyksistä. Maatalous, 19, p. 194-197. Porvoo-Helsinki.

1927 - Etelä-Pohjanmaa. Summary: South East-Bothnia. Agrogeol. karttoja N:o 5, p. 1-78, 10 kuvaa, 17 taul., 4 karttaa (1: 100.000). Helsinki. Myös ruotsiksi (Auch auf Schwedisch).

- Superfosfaatin käyttö happamilla mailla. Maatalous, 20, p. 144. Porvoo-Helsinki.

— Savimaat ja niiden viljeleminen. Pellervo, 28, p. 330-332. Helsinki.

- Suomudan käyttö pelloillamme. Ibid., 28, p. 693-694.

— Peltomaiden kuntoisuudesta. Ibid., 28, p. 763-765.

— Eräitä uudempia tutkimuksia karjanlannasta ja sen säilyttämisestä. Ibid., 28, p. 805-807.

- Influence of absorbed ions on soil reaction. Agrogeol. julk. N:o 22, p. 1-13. Helsinki.

- M. J. Kotilaisen kanssa (mit M. J. Kotilainen). Etelä-Hämeen maaperä. I. Kivennäismaalajit, B. Aarnio, p. 14-22, 4 kuvaa. II. Turvemaat, M. J. Kotilainen, p. 22-26. Talonpoika 4. Etelä-Häme, p. 14-26. Porvoo.

- Antri Salmisen kanssa (mit Antti Salminen). Die Änderung der Reaktion durch altern der Bodenproben. Verhandl. der II. Komm. Int. Bodenk. Ges., Vol. B, p. 30-33. Groningen.

1928 - Lounais-Suomen savityypit. Ref.: Die Tontypen in SW-Finnland. Agrogeol. julk. N:o 28, p. 1-21. Helsinki.

— Eräitä näkökohtia tilusten jyvityksessä. Ref.: Beobachtungen zur Bonitierung des Bodens. Maanmittaus, 2, p. 160-164. Helsinki.

- Maaperäsuhteet kasvituotannon edellytyksenä. Maa ja metsä 1, p. 51-90, 1 kartta. Porvoo.

- Syd-Österbotten. Summary: South East-Bothnia, p. 76-79. Agrogeol. kartor N:o 5, p. 1-75, 4 karttaa $(1: 100.000)$. Helsinki.

- Lannoitusaineiden vaikutus maan ominaisuuksiin. Pellervo, 29 p. 307-310. Helsinki.

— Kotieläinlanta ja väkilannat. Ibid., 29, p. 395-398.

- Maan happamuutta parantavista aineista. Maatalous, 21, p. 22-24. Porvoo- Helsinki. 
— Eräitä viljelysmaiden ominaisuuksiin vaikuttavia seikkoja. Ibid., 21, p. 117-120. Porvoo - Helsinki.

— Suomen maaperä ja sen kuivatus. Viides maataiousviikko, p. 78-90. Porvoo.

- Etelä-Pohjanmaan maaperä. Talonpoika 5. Etelä-Pohjanmaa, p. 43-54. Porvoo.

- Die Veränderung des Aziditätsgrades durch Trocknen der Bodenproben. Agrogeol. julk. N:o 26, p. 1-11. Helsinki.

- Die Pecherde - (Terre bitoumineuse. - Pitchlike soil). Soil Research — Bodenkundliche Forschungen - Recherches sur le Sol, Bd. I N:o 2, p. 92-95. Berlin.

— Om järnets vandring i podsoljordar. Geol. Fören. i Stockholm förhandl., 50, p. 459-460. Stockholm.

- Influence of absorbed ions on soil reaction. Proc. and papers of I. Int. Congr. of Soil Sci. June 13-22, 1927 Washington, Vol. II, p. 65-76. Washington. Myös saksaksi (Auch auf Deutsch).

- Chemical and physical properties of Finnish soils. Proc. and papers of I. Int. Congr. of Soil Sci. June 13-22, 1927 Washington, Vol.IV, p. 507-523, 1 kartta. Washington.

1929 - Onko maan reaktio muuttumaton suure? Ref.: Ist die Reaktion des Bodens eine unveränderliche Grösse? Maataloustiet. aikak., 1, p. 18-25. Helsinki.

- Maan reaktion määrääminen kenttätutkimuksissa. Summary: Some Comparisons of the Electrometric and the Colorimetric Measurements of the Soil Reaction. Ibid., 1, p. 125128. Helsinki.

- Maanviljelyskoetoiminnan organisatio. Ref.: Die Organisation des landwirtschaftlichen Versuchswesens in Finnland. Acta agr.fenn., 18, p. 109-115. Helsinki.

- Itä-Savon maaperä. Talonpoika 6. Itä-Savo, p. 33-36. Porvoo.

- Raakafosfaatit ja niiden käyttö. Pellervo, 30, p. 139-142. Helsinki.

- Maanparannusaineina käytetyistä maalajeista. Ibid., 30, p. 999-1001.

- Liian happamuuden poistaminen laidunmailta. Sucmen Laiduntalous I, p. 7-14. Lahti.

- Die Einwirkung von adsorbierten Ionen auf die Bodenreaktion. Verh. II. Komm. Int. Bodenk. Ges., Teil A, p. 98-100. Budapest.

— Valtion toimeenpanemat maatutkimukset. Maa ja metsä, 6, p. 771-772. Porvoo.

- De absorberande ionernas inverkan på jordens egenskaper. Beretn. om N.J.F:s 4. Kongr. Helsingfors, Juli 1929, p. 323-328. København.

- Werden die Bodenproben beim Trocknen saurer? Ztschr. Pfl., Düng. u. Bodenk., Teil A, 14, p. $37-39$. Berlin.

1930 - Turku. Engl. Summary. Agrogeol. karttoja N:o 6, p. 1-40, 2 karttaa (1:50.000). Helsinki.

— Pohjois-Hämeen maaperä. Talonpoika 7. Pohjois-Häme, p. 32-36. Porvoo.

- Kalkki maanparannusaineena. Pellervo, 31, p. 141-145. Helsinki.

- Maatutkimukset Suomessa. Suomen Pellot, 2, p. 3-6. Helsinki.

- Maalajit. Suomen Laiduntalous, 2, p. 24-32. Helsinki.

- Salt soils in Finland. Selostus: Suomen suolamaat. Maataloustiet. aikak., 2, p. $39-47$. Helsinki.

1931 - Maaperäoppi, p. 1-194, 37 kuvaa. Porvoo.

- Agrogeologinen tutkimustyö maassamme. Valtion Maatutkimuslatos, Kansantajuisia julkaisuja N:o 2, p. 1-29. Helsinki.

- Suomen viljelyskelpoisista maista. Maatalous, 24, p. 334-336. Helsinki.

- Maan lannoitustarpeen määräämisestä. Summary: On the chemical determination of available plant food in soils. Maataloustiet. aikak., 3, p. 84-90. Helsinki.

- Viljelysmaiden rikkaruohojen suhde maan reaktioon. Summary: The dependence of weeds upon the reaction of soil. Ibid., 3, p. 117-121.

- Pohjois-Pohjanmaan maaperä. Talonpoika, 8. Pohjois-Pohjanmaa, p. 33-36. Porvoo.

1932 - Vuosikertomus Valtion Maatutkimuslaitoksen toiminnasta v. 1931. Jahresbericht über die Tätigkeit des Staatlichen Bodenuntersuchungsinstituts im Jahre 1931, p. 1-20. Helsinki. 
- The dependence of weeds upon the reaction of soil. Suomen Kemistilehti, B, p. 32. Helsinki.

- H. Lönnrothin kanssa (mit H. Lönnroth). Kivennäismaittemme kalkintarve. Ref.: Der Kalkbedarf der Mineralböden in Finnland. Agrogeol. julk. N:o 31, p. 1-15. Helsinki; Maataloustiet. aikak., 4, p. 20-32. Helsinki; Suomen Kemistilehti, B,p. 32, Helsinki.

1933 - Vuosikertomus Valtion Maatutkimuslaitoksen toiminnasta v. 1932. Jahresbericht über die Tätigkeit des Staatlichen Bodenuntersuchungsinstituts im Jahre 1932, p. 1-19. Helsinki.

— Loimaa. Engl. Summary. Agrogeol. karttoja N:o 7, p. 1-56, 4 karttaa (1 : 50.000). Helsinki.

- Uudempia tutkimuksia maan happamuuden, kasvinravintoainepitoisuuden ja satojen välisistä suhteista. Maatalous, 26, p. 126-128. Porvoo-Helsinki.

- Die Pflanzennährstoffverhältnisse der Finnischen Böden. Mezögazdasági Kutatások, Sigmond-Sonderheft 1933, p. 431-438. Budapest.

- Kasvinravintoainesuhteista metsämaiden humuspitoisessa kerroksessa. Ref.: Pflanzennährstoffverhältnisse in der humushaltigen Schicht des Waldbodens. Maataloustiet. aikak., 5, p. 63-70. Helsinki.

- Uudenmaan maaperä. Talonpoika 9. Uusimaa, p. 43-48. Porvoo-Helsinki.

1934 - Vuosikertomus Maatalouskoelaitoksen maatutkimusosaston toiminnasta v. 1933. Jahresbericht über die Tätigkeit der Bodenkundlichen Abteilung der Landwirtschaftlichen Versuchsanstalt im Jahre 1933, p. 1-26. Helsinki.

- Maanparannusaineista. Maatalous, 27, p. 4-6. Porvoo-Helsinki.

- Über die Einwirkung der Gesteinsarten auf die Pflanzennährstoffe des Naturbodens. Agrogeol. julk. N:o 35, p. 1-20. Helsinki.

- Maan happamuus tanskalaisten kokeiden valossa. Maatalous, 27, p. 130-134. Porvoo Helsinki.

1935 - Vuosikertomus Maatalouskoelaitoksen maatutkimusosaston toiminnasta v. 1934. Jahresbericht über die Tätigkeit der Bodenkundlichen Abteilung der Landwirtschaftlichen Versuchsanstalt im Jahre 1934, p. 1-30. Helsinki.

- Salo I. Engl. Summary. Agrogeol. karttoja N:o 8, Soil maps, p. 1-46, 1 kartta (1: 50.000). Helsinki.

- On the factors acting upon the qualities of the humus containing layer of natural soils. Selostus: Luonnontilaisten maiden humuspitoisen kerroksen ominaisuuksiin vaikuttavista seikoista. Agrogeol. julk. N:o 39, p. 1-14, 3 karttaa. Helsinki; Maataloustiet. aikak., 7, p. 73-84. Helsinki.

- Über den Einfluss von Kalk auf die Reaktion des Bodens und über die Reaktionsschwankungen während der Vegetationsperiode. Selostus: Kalkin vaikutuksesta maan reaktioon ja reaktiovaihteluista kasvukautena. Maataloustiet. aikak., 7, p. 153-170. Helsinki; Agrogeol. julk. N:o 41, p. 1-20. Helsinki.

- De agrogeologiska kartläggningarna in Finland. Beretn. om N.J.F:s 5. Kongr. København Juli 1935, Nordisk Jordbrugsf., p. 358-361. København.

- Peltomaa. Suomen Pellot, 6, p. 3-6. Helsinki.

- Maaperän viljelysominaisuuksista. Maatalous, 28, p. 152-154, 156. Porvoo-Helsinki.

— Om jordarternas benämningar (nomenklatur). Tidskrift för lantmän, 2, p. 25-27. Turku.

— De klimatiska faktorernas inverkan på jordens odlingsegenskaper. Beretn. om N.J.F:s 5. Kongr. København Juli 1935, Nordisk Jordbrugsf., p. 423-428. København.

— Über einige auf das Pflanzenwachstum einwirkende Faktoren. Vortrag 11. 5. 1935. Sitzungsberichte der Finnische Akademie der Wissenschaften 1935, p. 92-105. Helsinki.

- Suomen maaperä ja sen kuivatus. Suomen Salaojitusyhdistyksen julk. 10, 2 p. Porvoo; eripainos julkaisussa "Viides maatalousviikko», 1928, p. 78-90. Porvoo.

1936 - Vuosikertomus Maatalouskoelaitoksen maatutkimusosaston toiminnasta v. 1935. Jahresbericht über die Tätigkeit der Bodenkundlichen Abteilung der Landwirtschaftlichen Versuchsanstalt im Jahre 1935, p. 1-26. Helsinki.

— Viljelyskelpoisen maan arvioiminen erikoisesti asutustoimintaa silmälläpitäen. Maatalous, 29, p. 18-21. Porvoo - Helsinki. 
- Salo II. Agrogeol. karttoja N:o 9, Soil maps, p. 1-43, 1 kartta (1:50.000). Helsinki.

- Die bodenkundlichen Untersuchungen in Finnland. Bericht über den 5. Kongress im Juni 1935 in Helsinki (Agronomenverband der Baltischen Staaten), p. 114-119. Helsinki.

- The soils of Finland. Finland Year Book 1936 by I. Leiviskä, p. 46-50, 1 kartta. Helsinki. Myös suomeksi (Auch auf Finnisch).

- Mineralogian, geologian ja maaperäopin alkeet. p. 1-48, 1 kartta. Porvoo-Helsinki.

- Eri maalajien happamuussuhteista hedelmäpuitten juurialueen eri syvyyksillä. Puutarha ja Koti, 2, p. 8-9. Helsinki.

- Eräistä maan kasvukykyyn vaikuttavista seikoista. Esittänyt 11. 5. 1935 B. Aarnio. Suomalainen Tiedeakatemia. Esitelmät ja pöytäkirjat 1935, p. 81-92. Helsinki. Myös saksaksi (Auch auf Deutsch).

1937 - Vuosikertomus Maatalouskoelaitoksen maatutkimusosaston toiminnasta v. 1936. Jahresbericht über die Tätigkeit der Bodenkundlichen Abteilung der Landwirtschaftlichen Versuchsanstalt im Jahre 1936, p. 1-27. Helsinki.

— Salo III. Agrogeol. karttoja N:o 10 Soil maps, p. 1-42, 1 kartta (1:50.000). Helsinki.

- Hedelmäpuiden kasvupaikasta. Puutarha ja Koti, 1, p. 3-7. Helsinki.

— Maaperätutkimukset Suomessa. Maan Suola, 9, p. 8-9. Helsinki.

- Voidaanko savimaat luokitella mekaanisen kokoomuksensa perusteella. Ref.: Kann man auf Grund der mechanischen Zusammensetzung die Tonböden klassifizieren. Maataloust. aikak., 9, p. 149-151. Helsinki.

— Über Gyttjaböden. Bodenk. u. Pflanzenern., Bd. 2 (47), p. 186-192. Berlin.

- Die Untersuchungen der Bodenkundlichen Abteilung der Landwirtschaftlichen Versuchsanstalt Finnlands in den letzten Jahren. Forschungsdienst, III : 6, p. 288-290. Berlin.

— Miksi meidän pitää lannoittaa peltojamme. Suomen Pellot, 8, p. 6-10. Helsinki.

- Dépots quaternaires et sol. La Finlande en 1937. p. 41-45. Helsinki.

1938 - Vuosikertomus Maatalouskoelaitoksen maatutkimusosaston toiminnasta v. 1937. Jahresbericht über die Tätigkeit der Bodenkundlichen Abteilung der Landwirtschaftlichen Versuchsanstalt im Jahre 1937, p. 1-33. Helsinki.

- Moreenin mekaaninen kokoomus Suomessa. Ref.: Die mechanische Zusammensetzung der Moräne in Finnland. Agrogeol. julk. N:o 45, p. 1-14. Helsinki.

- Die mechanische Zusammensetzung der Moräne in Finnland. Selostus: Moreenin mekaaninen kokoomus Suomessa. Maataloustiet. aikak., 10, p. 1-11. Helsinki.

- Über die Tone Finnlands und ihre Eigenschaften. Selostus: Suomen savista ja niiden ominaisuuksista. Agrogeol. julk. N:o 46, p. 1-27. Helsinki.

- Salo IV. Ruotsinkiel, selostus. Agrogeol. karttoja N:o 11, p. 1-20, 1 kartta (1:50.000). Helsinki.

- Die Bodenkundlichen Untersuchungen in Finnland. Die Ernährung der Pflanze, 34, p. 205-207. Berlin.

- De agrogeologiska kartläggningarna i Finland. Mjölkpropagandan, XV:2, p. 46. Stockholm.

- Om egenskaperna hos Finlands leror. Beretn. om N.J.F:s 6. Kongr. Uppsala, Juli 1938, Nordisk Jordbrugsf. N:o 4-7, p. 336-341. København.

- Der Gebrauch der Kunstdünger und ihre Einwirkung auf die Erträge in Finnland. F.I.T.A. Ier Ier Congr. Int. des Engr. Chim., Rome 3. -6. Oct. 1938, p. 1-5. Rome.

- Mihin tuloksiin on tultu karjalannan erilaisista säilytystavoista. Suomen Pellot, 9, p. 3-5. Helsinki,

- Hivenaineiden biologinen merkitys. Ibid., p. 74-75.

- Konferenz der II. Komm. und der Alkali-Subkommission in Helsinki, Finnland, vom 26. bis 30. 7. 1938. Mitt. Int. Bodenk. Ges., 13, p. 1-6. Berlin. Myös englanniksi ja ranskaksi (Auch auf Engl. u. Franz.).

- Erkki Kivisen kanssa (mit Erkki Kivinen). Die Böden Finnlands. Agrogeol. julk. N:o 47, p. $1-30$ (B. Aarnio: Die Mineralböden Finnlands, p. 3-17). Helsinki; Verhandl. der 
II. Kommission und der Alkali-Subkommission der Int. Bodenk. Ges. Helsinki 26. - 30. 7 . 1938, Vol. A, p. 103-117. Helsinki.

- Erki Kivisen kanssa (mit Erkki Kivinen). Verhandl, der II. Komm. und der AlkaliSubkomm. Int. Bodenk. Ges. Helsinki 26.-30. 7. 1938, Vol. A, p. $130(+1)$. Helsinki.

- Erki Kivisen kanssa (mit Erki Kivinen). Verhandl. der V. Komm. Int. Bodenk. Ges. Helsinki 26.-30. 7. 1938, Vol. A, p. 1-92. Helsinki.

- F. Zuckerin ja Erki Kivisen kanssa (mit F. Zucker und Erki Kivinen). Verhandl. der II. Komm. und der Alkali-Subkomm. Int. Bodenk. Ges. Helsinki 26. -30. 7. 1938, Vol. B, p. 1-112. Helsinki.

1939 - Vuosikertomus Maatalouskoelaitoksen maatutkimusosaston toiminnasta v. 1938. Jahresbericht über die Tätigkeit der Bodenkundlichen Abteilung der Landwirtschaftlichen Versuchsanstalt im Jahre 1938, p. 1-25. Helsinki.

- Mineralogian, geologian ja maaperäopin oppikirja maa- ja metsätaloutta varten, p. 1163, 1 kartta. Porvoo - Helsinki.

- Karjanlannan säilytystavoista. Maan Suola, 2, p. 23. Helsinki.

- Die neuen Ergebnisse der Bodenforschung und ihre Bedeutung für die praktische Landwirtschaft. XVIII. Int. Landwirtsch. Kongress in Dresden. Sektion IV Pflanzenbau. Hauptberichte. p. 93-97. Dresden.

1940 - Savistamme ja niiden viljelysominaisuuksista. Maatalous, 33, p. 5-7. Forssa - Helsinki.

— Siirtoväen maansaantimahdollisuudet. Ibid., 33, p. $73-76$.

- Changes in the surface layer of the soil. Selostus: Maan pintakerroksen muttuminen. Maataloustiet. aikak., 12, p. 78-83. Hels inki.

1941 - Vuosikertomus Maatalouskoelaitoksen maatutkimusosaston toiminnasta v. 1939 ja 1940. Jahresbericht über die Tätigkeit der Bodenkundlichen Abteilung der Landwirtschaflichen Versuchsanstalt im Jahren 1939 und 1940, p. $9+14$. Helsinki.

- Maaperän vesitalous. Maatalous, 34, p. 180-183. Forssa-Helsinki.

- Jouko Vuorisen kanssa (mit Jouko Vuorinen). Lannoitus. Joka talon opas N:o 1, p. 1-161. Helsinki.

1942 - Ueber die Tone Finnlands und ihre Eigenschaften. II. Die Austauschbaren Basen. Agrogeol. julk. N: o 53, p. 1-24. Helsinki.

- Maatalouskoelaitoksen maatutkimusosaston tutkimukset. Maa, 27, p. 407_409. Helsinki.

- Viljelyskelpoisten maiden inventoiminen. Ibid., 27, p. 439-440.

- Suomen savista ja niiden ominaisuuksista. Ref.: Über die Tone Finnlands und ihre Eigenschaften. Maataloustiet. aikak., 14, p. 1-18, Helsinki.

- Kulttuuritoimenpiteiden vaikutus maan pintakerroksen kasvinravintoainepitoisuuteen. Maatalous, 35, p. 103-105. Forssa-Helsinki.

- Suolamaista. Ibid., 35, p. $231-232$.

1943 - Vuosikertomus Maatalouskoelaitoksen maatutkimusosaston toiminnasta v. 1941 ja 1942. Jahresbericht über die Tätigkeit der Bodenkundlichen Abteilung der Landwirtschaftlichen Versuchsanstalt im Jahren 1941 und 1942, p. 1-13. Helsinki.

- Maassa olevien fosforiyhdistysten liukoisuuden lisääntyminen kuumentamisen vaikutuksesta. Maatalous, 36, p. 88-90. Forssa - Helsinki.

1944 - Eräitä piirteitä Aunuksen piirin maaperästä. Ref.: Einige Züge zur Kennzeichnung des Bodens im Bezirk Aunus. Agrogeol. julk. N:o 55, p. 1-12. Helsinki; Maataloust. aikak., 16, p. 63-74. Helsinki.

1945 - Maaperätutkimukset Suomessa. Työväen Kalenteri 1946, p. 74-78. Helsinki.

1946 - Vuosikertomus Maatalouskoelaitoksen maatutkimusosaston toiminnasta v. 1943 ja 1944. Jahresbericht über die Tätigkeit der Bodenkundlichen Abteilung der Landwirtschaftlichen Versuchsanstalt im Jahren 1943 und 1944, p. 1-5. Helsinki.

- E. K. KiveккӓÄn kanssa (mit E. K. KiveкÄs). Maantutkimusopas. p. 1-104. Helsinki.

1948 - Vilken nytta ha vi av jordartskartor eller s.k. markkartor. Nordisk Jordbrugsf. 1948 N:0 4-6, p. 784-789. København. 
1949 - Jouko Vuorisen ja muiden kanssa (mit Jouko Vuorinen und andere). Maaperäsanaston ja maalajien luokituksen tarkistus v. 1949. Summary: A critical review of soil terminology and soil classification in Finland in the year 1949 p. 55-66. Maataloustiet. aikak., 21, p. 37-54. Helsinki. Myös ruotsiksi (Auch auf Schwedisch); Markterminologin och jordarternas indelning granskad år 1949. Svenska lantbrukssällskapens i Finland förbund julk. 130, p. 1-26. Helsinki. 